\title{
Growth of tobacco hairy roots with constitutive expression of the NtEXPA5 expansin gene
}

Kuluev B.R., Musin H.G., Gumerova G.R., Chemeris A.V.

Institute of Biochemistry and Genetics - Subdivision of the Ufa Federal Research Centre of the Russian Academy of Sciences,

Ufa, Russia

E-mail:kuluev@bk.ru

Key message. Tobacco hairy roots with constitutive expression of the NtEXPA5 expansin gene were obtained and analyzed, which were characterized by higher growth rates and increased productivity under normal conditions, as well as the action of stress factors.

Keywords: expansins, hairy roots, salinity, heavy metals, Nicotiana tabacum

Expansins are non-enzymatic proteins involved in the softening of cell walls, the mechanism of action of which is associated with the weakening and breaking of hydrogen bonds between xyloglucans and cellulose microfibrils. Earlier, the protective role of expansins under the influence of stress factors such as drought, heat, and salinity was shown using transgenic plants. In addition to transgenic plants, a promising system for the production of biologically active substances is hairy roots cultures, which in biotechnological production can also be exposed to stress factors associated with changes in the composition of the medium, temperature, etc. Therefore, the creation of not only highly productive, but also stress-resistant hairy roots is very important. Based on this, the goal of our work was to obtain hairy roots of tobacco with constitutive expression of the NtEXPA5 expansin gene and evaluate their growth parameters under normal cultivation conditions and under the action of stress factors. To obtain hairy roots, transgenic tobacco plants Nicotiana tabacum L. cultivars of the Petit Havana strain SR1 line with the constitutive expression of the NtEXPA5 gene of generation T3, which we obtained earlier, were subjected to Agrobacterium-mediated transformation using Agrobacterium rhizogenes. The constitutive expression of the NtEXPA5 tobacco expansin gene promoted higher growth rates and increased productivity of hairy roots under normal conditions. Tobacco hairy roots overexpressing the NtEXPA5 gene were characterized by increased tolerance to $\mathrm{NaCl}$, mannitol, cadmium acetate and $\mathrm{CuSO}_{4}$. Based on the obtained data, our tested genetic engineering construct with the NtEXPA5 gene can be proposed for obtaining hairy roots with improved growth parameters and increased productivity under both normal and stress conditions. As part of this work, we are discussed the prospects of using hairy roots of tobacco as a model object for quick testing of targeted genetically engineered constructs designed for creation of transgenic plants.

This work was supported by the RFBR grant No. 18-04-00118 A.

\section{Рост волосовидных корней табака с конститутивной экспрессией гена экспансина $\mathrm{NtEXPA5}$}

Кулуев Б.Р., Мусин Х.Г., Гумерова Г.Р., Чемерис А.В.

Институт биохимии и генетики - обособленное структурное подразделение Федерального государственного

бюджетного научного учреждения Уфимского федерального исследовательского центра Российской академии наук, Уфа, Россия

\begin{abstract}
Аннотация. Были получены и проанализированы волосовидные корни табака с конститутивной экспрессией гена экспансина NtEXPA5, которые характеризовались более высокими темпами роста и повышенной продуктивностью
\end{abstract} при нормальных условиях, а также действии стрессовых факторов.

Ключевые слова: экспансины, волосовидные корни, засоление, тяжелье металль, Nicotiana tabacum

Экспансины - это неферментативные белки участвующие в размягчении клеточных стенок, механизм действия которых связан с ослаблением и разрывом водородных связей между ксилоглюканами и микрофибриллами целлюлозы. Ранее нами на примере трансгенных растений была показана защитная роль экспансинов при действии таких стрессовых факторов как засуха, жара и засоление. Кроме трансгенных растений перспективной системой для продуцирования биологически активных веществ являются культуры волосовидных корней (hairy roots), которые в биотехнологическом производстве также могут подвергаться действию стрессовых факторов, связанных с изменением состава среды, температуры и т.д. Поэтому создание не только высокопродуктивных, но и стрессоустойчивых волосовидных корней также весьма актуально. Исходя из этого, целью нашей работы стало получение волосовидных корней табака с конститутивной экспрессией гена экспансина NtEXPA5 и оценка их параметров роста при нормальных условиях культивирования и при действии стрессовых факторов. Для получения волосовидных корней использовали трансгенные растения табака Nicotiana tabacum L. copтa Petit Havana линии SR1 с конститутивной экспрессией гена NtEXPA5 поколения Т3, полученные нами ранее, которые подвергали агробактериальной трансформации при помощи Agrobacterium rhizogenes. Конститутивная экспрессия гена экспансина табака NtEXPA5 способствовала более высоким темпам роста и повышенной продуктивности волосовидных корней при нормальных условиях культивирования. Волосовидные корни табака сверхэкспрессирующие ген NtEXPA5 отличались повышенной устойчивостью к действию $\mathrm{NaCl}$, маннитола, ацетата кадмия и $\mathrm{CuSO}_{4}$. Исходя из полученных данных испытанная нами генно-инженерная конструкция с геном $N t E X P A 5$ может быть предложена для получения волосовидных корней с улучшенными параметрами роста и повышенной продуктивностью как при нормальных, так и при стрессовых условиях культивирования. В рамках проделанной работы нами обсуждается перспективность использования волосовидных корней табака как модельного объекта для быстрого тестирования целевых генно-инженерных конструкций, предназначенных для создания трансгенных растений.

Работа выполнена при поддержке гранта РФФИ № 18-04-00118 А. 